\title{
A Mitochondrial Membrane Exopolyphosphatase Is Modulated by, and Plays a Role in, the Energy Metabolism of Hard Tick Rhipicephalus (Boophilus) microplus Embryos
}

Eldo Campos ${ }^{1,2}$, Arnoldo R. Façanha ${ }^{2,3}$, Evenilton P. Costa ${ }^{3}$, Amanda Fraga ${ }^{1}$, Jorge Moraes ${ }^{1,2}$, Itabajara da Silva Vaz, Jr. ${ }^{2,4}$, Aoi Masuda ${ }^{2,5}$ and Carlos Logullo ${ }^{2,3, *}$

1 Laboratório Integrado de Bioquímica-Hatisaburo Masuda, UFRJ, Polo Barreto, Rua Rotary Club s/n, São José do Barreto, Macaé, RJ, C.P. 119.331, CEP 27971-220, Brazil;

E-Mails: eldocampos@macae.ufrj.br (E.C.); manda_fraga@yahoo.com.br (A.F.); jorgemoraes@bioqmed.ufrj.br (J.M.)

2 Instituto Nacional de Ciência e Tecnologia-Entomologia Molecular, Rio de Janeiro, RJ, CEP 21941-590, Brazil; E-Mails: arnoldo@uenf.br (A.R.F.); itabajara.vaz@ufrgs.br (I.d.S.V.); aoi@cbiot.ufrgs.br (A.M.)

3 Laboratório de Química e Função de Proteínas e Peptídeos, Laboratório de Biologia Celular e Tecidual and Unidade de Experimentação Animal-CBB-UENF, Avenida Alberto Lamego, 2000, Horto, Campos dos Goytacazes, RJ, CEP 28015-620, Brazil; E-Mail: eveniltonpessoa@yahoo.com.br

4 Centro de Biotecnologia e Faculdade de Veterinária, UFRGS, Avenida Bento Gonçalves, 9090, Porto Alegre, RS, C.P. 15005, CEP 91501-970, Brazil

5 Centro de Biotecnologia, UFRGS, Avenida Bento Gonçalves, 9500, prédio 43421, Porto Alegre, RS, C.P. 15005, CEP 91501-970, Brazil

* Author to whom correspondence should be addressed; E-Mail: logullo@uenf.br; Tel.: +55-22-2739-7134.

Received: 22 April 2011; in revised form: 14 May 2011 / Accepted: 19 May 2011 / Published: 3 June 2011

\footnotetext{
Abstract: The physiological roles of polyphosphates (polyP) recently found in arthropod mitochondria remain obscure. Here, the relationship between the mitochondrial membrane exopolyphosphatase (PPX) and the energy metabolism of hard tick Rhipicephalus microplus embryos are investigated. Mitochondrial respiration was activated by adenosine diphosphate using polyP as the only source of inorganic phosphate $\left(\mathrm{P}_{\mathrm{i}}\right)$ and this activation was much greater using poly $\mathrm{P}_{3}$ than poly $\mathrm{P}_{15}$. After mitochondrial subfractionation, most of the PPX activity was recovered in the membrane fraction and its kinetic analysis revealed that the affinity for poly $\mathrm{P}_{3}$ was 10 times stronger than that for polyP $\mathrm{P}_{15}$. Membrane PPX
} 
activity was also increased in the presence of the respiratory substrate pyruvic acid and after addition of the protonophore carbonyl cyanide-p-trifluoromethoxyphenylhydrazone. Furthermore, these stimulatory effects disappeared upon addition of the cytochrome oxidase inhibitor potassium cyanide and the activity was completely inhibited by $20 \mu \mathrm{g} / \mathrm{mL}$ heparin. The activity was either increased or decreased by $50 \%$ upon addition of dithiothreitol or hydrogen peroxide, respectively, suggesting redox regulation. These results indicate a PPX activity that is regulated during mitochondrial respiration and that plays a role in adenosine-5' -triphosphate synthesis in hard tick embryos.

Keywords: inorganic polyphosphate; respiration; membrane exopolyphosphatase; arthropod; energy metabolism

\section{Introduction}

Inorganic polyphosphates (polyP) are long chains of a few to several hundred phosphate residues linked by phosphoanhydride bonds. PolyP are ubiquitously found in all cell types examined to date and have been demonstrated to play diverse roles depending on the cell type and circumstances $[1,2]$.

The biological roles played by polyP have been studied most extensively in prokaryotes and unicellular eukaryotes, where they have been shown to regulate many biochemical processes, including metabolism and transport of inorganic phosphate $\left(\mathrm{P}_{\mathrm{i}}\right)$, cation sequestration and storage [1], formation of membrane channels [3,4], involvement in cell envelope formation and function in bacterial pathogenesis [5,6], regulation of gene and enzyme activities [7], activation of Lon proteases [8], and KcsA channel regulation [9]. Conversely, polyP functions have not been extensively investigated in higher eukaryotes, although some functions have been described, such as activation of TOR kinase [10], involvement in blood coagulation [11], and apoptosis [12-14]. Recently, we have reported the first evidence that polyP also play key roles in arthropods and have described a mitochondrial and a nuclear exopolyphosphatase involved in metabolism during embryogenesis of the hard tick Rhipicephalus microplus [15,16].

Exopolyphosphatase (PPX) splits $\mathrm{P}_{\mathrm{i}}$ off the end of a polyP chain and represents one of the main enzyme types responsible for polyP hydrolysis [1]. PolyP metabolism in eukaryotic cells shows specific peculiarities for different cellular compartments, including mitochondria [17]. At least two PPXs have been identified in Saccharomyces cerevisiae mitochondria [18], which possess their own polyP pool [19] that was described as a potential $\mathrm{P}_{\mathrm{i}}$ source for oxidative phosphorylation [20], these PPX are well characterized (PPX; polyphosphate phosphohydrolase; EC 3.6.1.11), however in higher eukaryotes the protein responsible for PPX activity is not known.

The present study is focused on $R$. microplus, a one-host tick that causes major losses to bovine herds, particularly in tropical regions; thus, major efforts have been directed toward developing immunoprophylactic tick-control tools [21]. Ticks are vectors of parasites that cause hemoparasitic diseases and are endemic in many cattle production areas [22]. R. microplus has one only host throughout its three life stages, usually a bovine host, and a long feeding period (approximately 21 days). Female ticks, after engorgement, drop off the host and initiate oviposition approximately 
three days later. Being an oviparous animal, embryogenesis occurs in the absence of exogenous nutrients and maternal nutrients are packaged in oocytes and stored mostly as yolk granules. Hatching occurs approximately 21 days after egg-laying and the emerging larvae can survive several weeks before finding a host, using the remaining yolk as the only energy source [23].

Here, we investigated mitochondrial membrane PPX regulation during mitochondrial respiration in $R$. microplus embryos, revealing an important role for this enzyme in tick energy metabolism.

\section{Results and Discussion}

Although the first evidence for the presence of polyP in mammalian cells were obtained long ago [24], since then relatively few studies have addressed their physiological roles in animal cells $[1,10,11,13-16,25,26]$.

Early $R$. microplus embryonic stages are similar to those of D. melanogaster and mosquitoes $[27,28]$. Tick embryogenesis is characterized by formation of a non-cellular syncitium up to day 4. Thereafter, the embryo becomes a multicellular organism and initiates organogenesis [29]. Previously, we have found that during egg segmentation (9th day after oviposition), a strong mitochondrial PPX activity exists [15]. Here, we provide evidence that mitochondrial membrane PPX plays a role in energy metabolism of $R$. microplus during embryo development.

\subsection{Characterization of Isolated Mitochondria}

Mitochondria from tick embryos in the segmentation stage (9th day after oviposition) were isolated and cellular respiration was measured using pyruvate as the substrate. Oxygen consumption was $30 \mathrm{nmol} / \mathrm{min} \cdot \mathrm{mg}$ protein and the RCR (respiratory control ratio) was 6.5 . The process was $\mathrm{KCN}$ - and oligomycin-sensitive (Table 1).

Table 1. Mitochondria isolation from R. microplus embryos on the 9 th day of embryogenesis.

\begin{tabular}{cccc}
\hline & State 3 & State 3 & RCR \\
\hline Mitochondria & $30.2 \pm 3.2$ & $4.6 \pm 0.7$ & $6.5 \pm 0.4$ \\
\hline
\end{tabular}

Respiratory parameters of mitochondria in the presence of pyruvate $(5 \mathrm{mM})$. The rates of respiration in State 3 (phosphorylating respiratory rate) and in State 4 (non-phosphorylating respiratory rate) are expressed as $\mathrm{nmol} \mathrm{O}_{2} / \mathrm{min} \cdot \mathrm{mg}$ protein. The results represent mean $\pm \mathrm{SD}$. of three independent experiments.

\subsection{Influence of Membrane PPX in Mitochondrial Respiration}

We have previously demonstrated that polyP can be used as a $\mathrm{P}_{\mathrm{i}}$ donor for adenosine-5'-triphosphate (ATP) synthesis in ticks [15]. To investigate the location of mitochondrial PPX, we assayed oxygen consumption using poly $\mathrm{P}_{3}$ and poly $\mathrm{P}_{15}$ as substrates and heparin as a PPX inhibitor. adenosine diphosphate-dependent mitochondrial oxygen consumption could be measured in the presence of poly $\mathrm{P}_{3}$ and poly $\mathrm{P}_{15}$ and in the absence of any other source of $\mathrm{P}_{\mathrm{i}}$, supporting the hypothesis previously postulated that polyP can be used as a $\mathrm{P}_{\mathrm{i}}$ donor for ATP synthesis [15]. However, this consumption 
was inhibited by heparin. Subsequently, oxygen consumption was recovered when $5 \mathrm{mM} \mathrm{P}_{\mathrm{i}}$ was added, which was interrupted by addition of oligomycin, an ATP-synthase inhibitor (Figure 1A and 1B). Oxygen consumption was distinct using both polyP: no statistical difference was found using poly $\mathrm{P}_{3}$ compared with $\mathrm{P}_{\mathrm{i}}$; otherwise, oxygen consumption was lower when poly $\mathrm{P}_{15}$ was used (Figure 1C).

Figure 1. Involvement of membrane PPX in mitochondrial respiration. Oxygen consumption was monitored using a reaction buffer in the absence of a $\mathrm{P}_{\mathrm{i}}$ source in eggs on the 9th day of development. In (A) and (B), the addition of $1 \mathrm{mM}$ ADP, $5 \mathrm{mM}$ pyruvate, $0.5 \mu \mathrm{M}$ polyP $\mathrm{P}_{3 \text { and } 15}, 20 \mu \mathrm{g} / \mathrm{mL}$ heparin, $5 \mathrm{mM} \mathrm{P}_{\mathrm{i}}$ and $0.5 \mu \mathrm{M}$ oligomycin is represented in the figure. This experiment was repeated at least three times with different preparations, and this figure shows a representative experiment. In $(\mathbf{C})$, the oxygen consumption was quantified using $1 \mathrm{mM}$ ADP, $5 \mathrm{mM} \mathrm{P}_{\mathrm{i}}, 5 \mathrm{mM}$ pyruvate and $0.5 \mu \mathrm{M}$ polyP $\mathrm{P}_{3}$ and 15 . Asterisk (*) denotes the difference between population and the significance was determined by two way ANOVA test (Kruskal-Wallis).
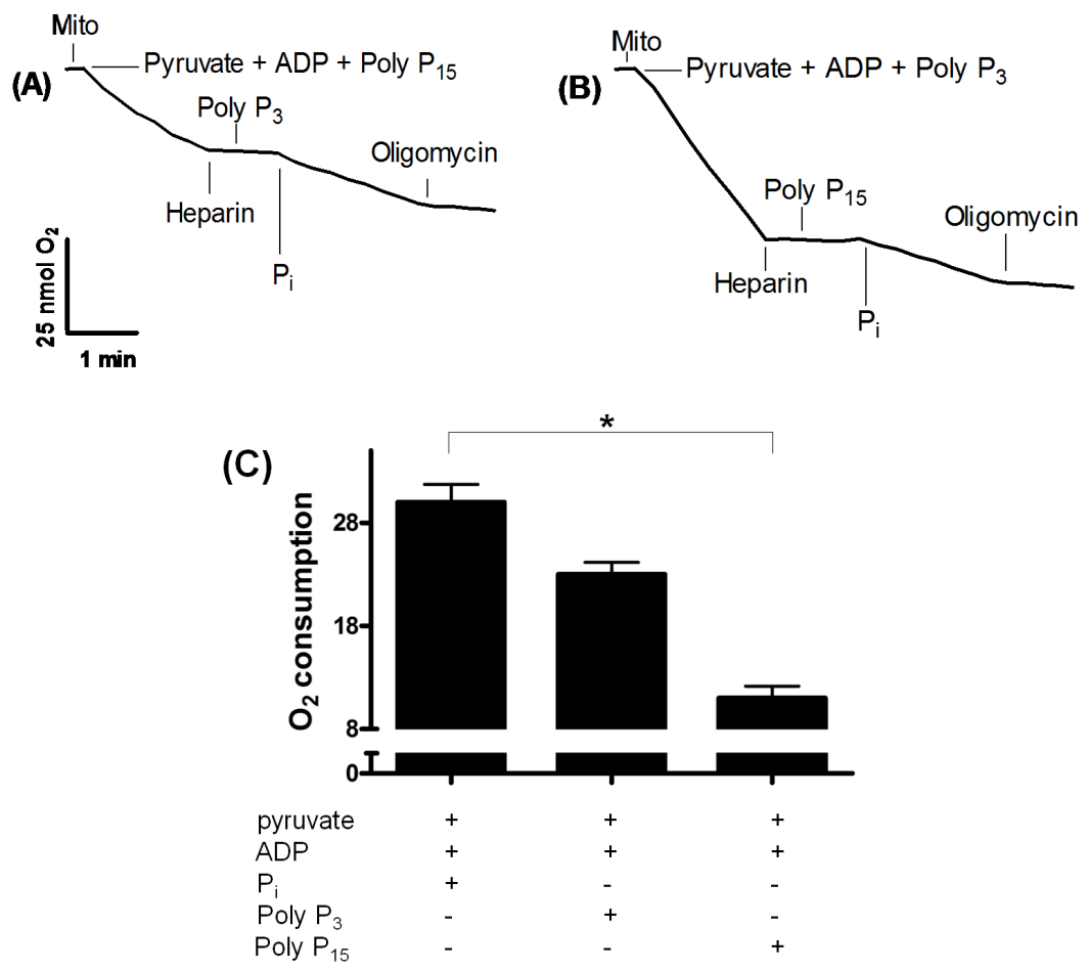

This new data suggest the existence of membrane PPX in this process due to the inhibition by heparin, which cannot cross the mitochondrial membrane, which has its active site oriented to the external face of the membrane. In fact, after subfractionation, the main PPX activity was recovered in the membrane fraction, supporting this hypothesis (Figure 2). 
Figure 2. PPX activity in mitochondrial preparations. PPX activity was measured in mitochondria (black bar), soluble (red bar) and membrane fractions (blue bar) of the eggs on the 9th day of development using polyP $\mathrm{P}_{3}$ as substrate. The activity was expressed as units per milligram of total protein and the results represent mean $\pm \mathrm{SD}$. of three independent experiments, in triplicate.

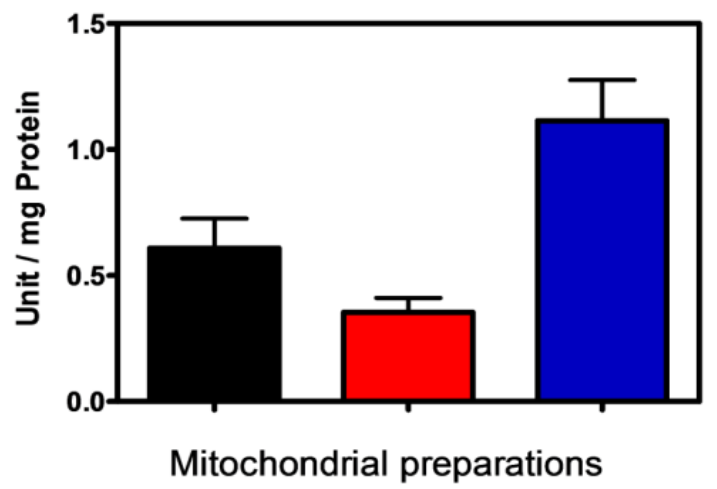

\subsection{Characterization of PPX Activity in Mitochondrial Membrane Preparation}

Exopolyphosphatases have been found in prokaryotes and eukaryotes, and although in bacteria these enzymes hydrolyze mostly high-molecular-weight polyP [17], at least some of the enzymes from S. cerevisiae and Leishmania major are more active in hydrolyzing short-chain polyP such as $\operatorname{polyP}_{3}[17,30]$.

To obtain insight into membrane PPX kinetics, the apparent $K_{m}$ was measured using polyP $\mathrm{P}_{3}$ and polyP $_{15}$ as substrates and results were expressed as the average of three independent experiments. Parameters obtained were very similar to those observed in crude mitochondria recently for our group [16]; the membrane PPX affinity for polyP $\mathrm{P}_{3}$ was 10 times stronger than for poly $\mathrm{P}_{15}$ (Table 2). These results are in contrast to those found in a mitochondria membrane-bound PPX of S. cerevisiae, in which case the affinity was stronger for long-chain polyP [31]. However, the new data demonstrated that membrane PPX kinetics are in agreement with oxygen consumption that was much higher using polyP $\mathrm{P}_{3}$ than polyP $\mathrm{P}_{15}$. Heparin, an effective inhibitor of PPX [1], blocked the activity (Table 2). These results reinforce the coupling existing between this enzyme activity and mitochondrial ADP phosphorylation.

Table 2. Characterization of PPX activity in membrane preparation of mitochondria of $R$. microplus embryos on the 9 th day of embryogenesis.

\begin{tabular}{|c|c|c|c|c|}
\hline Substrates & $\begin{array}{c}\mathbf{K m} \\
(\mu \mathbf{M})\end{array}$ & $\begin{array}{c}\text { Vmax } \\
\left(\mu \mathrm{mol} \cdot \mathrm{min}^{-1} \cdot \mathrm{mg}_{\text {protein }}{ }^{-1}\right)\end{array}$ & $\begin{array}{c}\text { Heparin } \\
\text { (\% inhibition) }\end{array}$ & $\begin{array}{c}\mathrm{O}_{2} \text { consumption } \\
\left(\text { nmol.min }^{-1} \cdot \mathrm{mg} \mathrm{protein}^{-1}\right)\end{array}$ \\
\hline $\mathrm{PolyP}_{3}$ & 0.2 & 2.4 & 98 & $23.85 \pm 2.06$ \\
\hline PolyP $_{15}$ & 2.2 & 1.1 & 98 & $11.44 \pm 1.79$ \\
\hline
\end{tabular}

\subsection{PPX Activity during Mitochondrial Respiration}

To further investigate regulation of membrane PPX during mitochondrial respiration, the activity was measured using pyruvate as the substrate and polyP as the only source of $\mathrm{P}_{\mathrm{i}}$. During this assay, 
addition of a small amounts of ADP $(0.2 \mathrm{mM})$ induces a state 3 followed by a state 4 , when all the ADP was converted to ATP. Thus, during state 3 , a balance exists between $\mathrm{P}_{\mathrm{i}}$ release by PPX and ATP synthesis because PPX is measured by the amount of $\mathrm{P}_{\mathrm{i}}$. Membrane PPX activity increased during mitochondrial respiration when pyruvate and ADP were added. This increase did not occur without ADP addition, indicating that PPX is stimulated during state 3 and the velocity of $\mathrm{P}_{\mathrm{i}}$ release is higher than ATP synthesis. Indeed, the stimulatory effect was antagonized by KCN (decreased electron flux) addition and increased by FCCP (increased electron flux) (Figure 3), suggesting that membrane PPX could be modulated by electron flux. These data are in agreement with our previous work in which we demonstrated that mitochondrial PPX activity is regulated by energy demand [15]. Additionally, these findings are consistent with those of [32], who demonstrated that production and consumption of mitochondrial polyP depend on the activity of the oxidative phosphorylation machinery in mammalian cells. Furthermore, heparin inhibited PPX activity completely, reinforcing the role of membrane PPX during mitochondrial respiration and the respiration activation by membrane PPX activity indicates that PPX could be close to the site of ATP production.

Figure 3. Regulation of mitochondrial PPX activity during mitochondrial respiration. PPX activity was measured in mitochondria of the eggs on the 9th day of development during mitochondrial respiration, using pyruvate as oxidative substrates, polyP $\mathrm{P}_{3}$ as $\mathrm{PPX}$ substrate, $\mathrm{KCN}$ as inhibitor of the respiratory chain, FCCP as uncoupler and Heparin as PPX inhibitor. The activity was expressed as units per milligram of total protein and the results represent mean \pm SD. of three independent experiments, in triplicate. Asterisk (*) denotes the difference between population and the significance was determined by two way ANOVA test (Kruskal-Wallis).

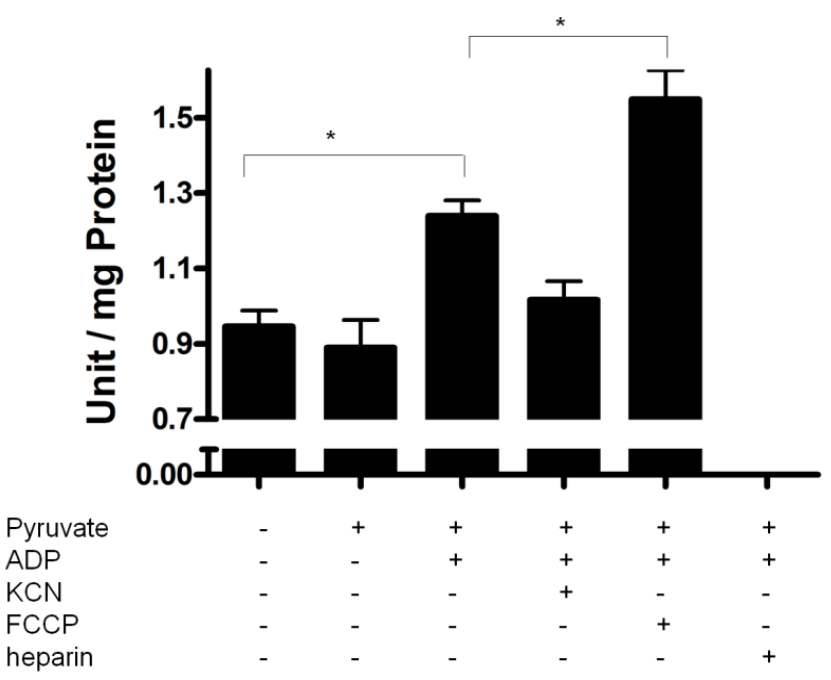

Additionally, mitochondrial polyP can form polyP/ $\mathrm{Ca}^{2+} / \mathrm{PHB}$ complexes [3] with ion-conducting properties similar to those of the native mitochondrial permeability transition pore [25]. Polyphosphatases localized in the membrane may not only degrade, but also synthesize polyP inside these complexes [31]. Recently, we demonstrated that synthesis of polyP occurs during embryogenesis of $R$. microplus in mitochondria, but not in nuclei [15,16]. As polyphosphate kinases have been found only in prokaryotes, the observation that polyP synthesis in ticks only occurs in the 
mitochondrial fraction supports the possibility that such synthesis probably occurs by the action of these complexes, as already suggested for other organisms [3,31,33,34].

\subsection{Mitochondrial Membrane PPX Redox Sensitivity}

Despite regulation of membrane PPX by increased or decreased electron flux, the sensitivity of this enzyme according to redox state using polyP $_{3}$ as the substrate was evaluated. The influence of dithiothreitol (DTT) and hydrogen peroxide $\left(\mathrm{H}_{2} \mathrm{O}_{2}\right)$ was investigated at different times and in a concentration range of 0.1 to $1.0 \mathrm{mM}$ and PPX activity was stimulated and inhibited by 50\%, respectively, suggesting that PPX is tightly regulated by redox state (Figure 4A and 4B).

Figure 4. Redox regulation of membrane mitochondrial PPX. PPX activity was measured in mitochondria of the eggs on the 9 th day of development using poly $\mathrm{P}_{3}$ as substrate. In (A), the activity was measured in the presence of $0.1-1.0 \mathrm{mM}$ of DTT (•) and $\mathrm{H}_{2} \mathrm{O}_{2}(\bullet)$.

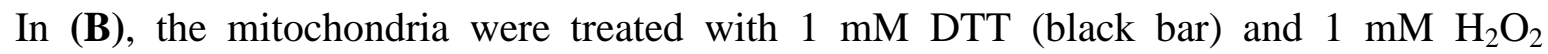
(hachured bar) for 0-20 min. The results represent mean \pm SD. of three independent experiments, in triplicate.
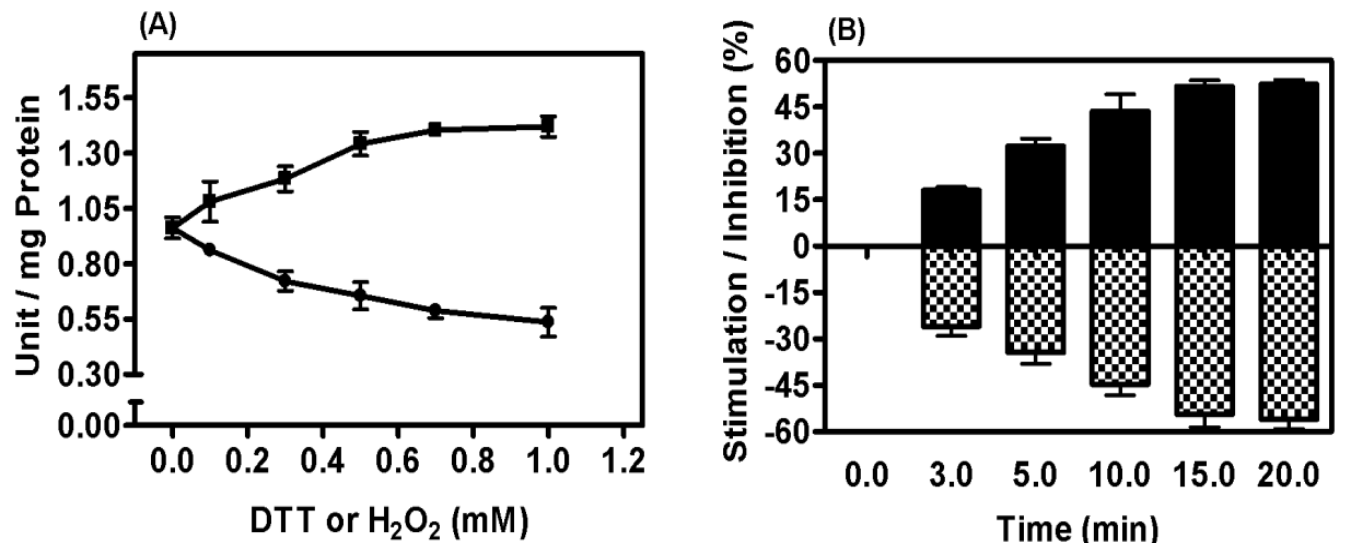

\section{Experimental Section}

\subsection{Ticks}

Ticks were obtained from a colony maintained at the Faculdade de Veterinária, Universidade Federal do Rio Grande do Sul (UFRGS), Brazil. R. microplus (Acarina, Ixodidae) ticks from the Porto Alegre strain, free of parasites, were reared on calves obtained from a tick-free area. Engorged adult females were maintained in Petri dishes at $28{ }^{\circ} \mathrm{C}$ and $80 \%$ relative humidity upon completion of oviposition, which starts approximately three days after adult ticks drop off calves. Animals were treated in compliance with the UFRGS review committee for animal care.

\subsection{Chemicals Materials}

$\mathrm{ADP}$, pyruvate, sodium phosphate glass type 15 (poly $\mathrm{P}_{15}$ ), sodium tripolyphosphate (poly $\mathrm{P}_{3}$ ), heparin, FCCP, oligomycin, $\mathrm{KCN}$, DTT, $\mathrm{H}_{2} \mathrm{O}_{2}$ were purchased from Sigma Adrich. All other reagents were analytical grade. 


\subsection{Isolation of Mitochondria}

The cell fractionation procedure used required large amounts of fresh eggs (at least $2 \mathrm{~g}$ ) to obtain functionally active mitochondrial fractions. For characterization of mitochondrial fractions, eggs in the segmentation stage (9th day after oviposition) were used and mitochondria were isolated as previously described [15]. Isolation of the mitochondria membrane fraction was performed by sonication of freshly prepared mitochondria three times for $20 \mathrm{~s}$ at the maximal output using an MSE ultrasonic disintegrator. The suspension was centrifuged for $10 \mathrm{~min}$ at $12,000 \times g$ to remove unbroken mitochondria. The supernatant was centrifuged at $100,000 \times g$ for $60 \mathrm{~min}$ to yield the mitochondria membrane fraction. The supernatant was a soluble preparation of mitochondria, which included both the intermembrane space and matrix, and the pellet was a mix of inner and outer membranes.

\subsection{PPX Assay and Kinetic Parameters}

The reaction mixture consisted of $50 \mathrm{mM}$ Tris- $\mathrm{HCl}$ buffer ( $\mathrm{pH} 7.5$ ) and $5 \mathrm{mM} \mathrm{MgCl}_{2}$, using $5 \mathrm{mM}$ poly $\mathrm{P}_{3}$ or poly $\mathrm{P}_{15}$, as the substrate. Reactions were performed at $30{ }^{\circ} \mathrm{C}$ for various time periods. The $\mathrm{P}_{\mathrm{i}}$ formed during the reaction was spectrophotometrically determined as previously described [35] by adding a solution of $0.5 \%$ ammonium molybdate, $0.35 \mathrm{M}$ sulfuric acid, $0.5 \%$ sodium dodecyl sulfate, and $10 \%$ ascorbic acid. Measurements of absorbance at $750 \mathrm{~nm}$ were performed after $15 \mathrm{~min}$. The enzyme amount liberating $1 \mu \mathrm{moL}$ of $\mathrm{P}_{\mathrm{i}}$ per $1 \mathrm{~min}$ was defined as one unit of enzyme activity (U). Protein concentration was measured as described previously [36] using bovine serum albumin as a standard.

PPX activity during mitochondrial respiration was measured using a reaction mixture consisting of $50 \mathrm{mM}$ Tris- $\mathrm{HCl}$ buffer ( $\mathrm{pH}$ 7.2), $120 \mathrm{mM} \mathrm{KCl}, 1 \mathrm{mM}$ EGTA, $5 \mathrm{mM} \mathrm{MgCl}_{2}$, and $0.2 \mathrm{mM}$ adenosine diphosphate $(\mathrm{ADP})$ in the absence of any $\mathrm{P}_{\mathrm{i}}$ source. $\mathrm{PolyP}_{3}(0.5 \mu \mathrm{M})$ was used as a substrate for PPX activity and $5 \mathrm{mM}$ pyruvate was used as an oxidative substrate. Potassium cyanide (KCN, $1 \mathrm{mM})$ and $20 \mu \mathrm{g} / \mathrm{mL}$ heparin were used to inhibit cytochrome oxidase and PPX activities, respectively, and $200 \mathrm{nM}$ carbonyl cyanide-p-trifluoromethoxyphenylhydrazone (FCCP) was used as ancoupler. The reaction was performed at $28^{\circ} \mathrm{C}$ for $15 \mathrm{~min}$ [15].

Kinetic parameters were estimated by nonlinear regression analysis applied to the Michaelis-Menten equation using the program package supplied by GraphPad Prism 5.0.

\subsection{Respiration Measurements}

The rate of $\mathrm{O}_{2}$ uptake by mitochondria was estimated with a Clark oxygen electrode (YSI, mod. 5775, Yellow Springs, OH, USA). The calibration process was conducted using the initial $\mathrm{O}_{2}$ concentration of the medium as $100 \% \mathrm{O}_{2}$-saturated buffer measured at $28{ }^{\circ} \mathrm{C}$. Measurements were performed in $1.5 \mathrm{~mL}$ of reaction buffer containing $120 \mathrm{mM} \mathrm{KCl}, 1 \mathrm{mM}$ EGTA, $0.2 \%$ bovine albumin, and $3 \mathrm{mM}$ HEPES ( $\mathrm{pH}$ 7.2) in the absence of any $\mathrm{P}_{\mathrm{i}}$ source, containing $0.5 \mathrm{mg} / \mathrm{mL}$ of mitochondrial protein. After a 1-min equilibration period, mitochondrial respiration was started by addition of pyruvate to a final concentration of $5 \mathrm{mM}$. Each experiment was repeated at least three times with different mitochondrial preparations. Figure 1 shows a representative experiment and other additions 
are indicated in the figure legend [15]. Respiratory control ratio (RCR) values were obtained with isolated mitochondria by using pyruvate as the complex I substrate.

\section{Conclusion}

The ubiquity of polyP and the variation in its chain length, location, and metabolism indicate the relevant functions of this polymer, including those in animal systems. The present study clearly demonstrates that electron flux and redox state may exert some influence and be influenced by the activity of membrane PPX, suggesting that it plays a role in energy supply during R. microplus embryogenesis.

\section{Acknowledgments}

This work was supported by grants from Fundação de Amparo à Pesquisa do Estado do Rio de Janeiro-FAPERJ, Conselho Nacional de Desenvolvimento Científico e Tecnológico-CNPq, Programa de Núcleos de Excelência-PRONEX, Programa Nacional de Cooperação Acadêmica-PROCAD-CAPES, Instituto Nacional de Ciência e Tecnologia/Entomologia Molecular-INCT/EM and FUNEMAC. The authors declare no conflicts of interest.

\section{References}

1. Kornberg, A.; Rao, N.N.; Ult-Riche, D. Inorganic polyphosphate: A molecule of many functions. Annu. Rev. Biochem. 1999, 68, 89-125.

2. Kulaev, I.; Kulakovskaya, T. Polyphosphate and phosphate pump. Annu. Rev. Microbiol. 2000, 54, 709-734.

3. Reusch, R.N. Poly-beta-hydroxybutyrate/calcium polyphosphate complexes in eukaryotic membranes. Proc. Soc. Exp. Biol. Med. 1989, 191, 377-381.

4. Jones, H.E.; Holland, I.B.; Jacq, I.B.; Wall, T.; Campbell, A.K. Escherichia coli lacking the AcrAB multidrug efflux pump also lacks nonproteinaceous, $\mathrm{PHB}-$ polyphosphate $\mathrm{Ca}^{2+}$ channels in the membrane. Biochim. Biophys. Acta 2003, 1612, 90-97.

5. Kim, K.S.; Rao, N.N.; Fraley, C.D.; Kornberg, A. Inorganic polyphosphate is essential for long-term survival and virulence factors in Shigella and Salmonella spp. Proc. Natl. Acad. Sci. USA 2002, 99, 7675-7680.

6. Rashid, M.H.; Rumbaugh, K.; Passador, L.; Davies, D.G.; Hamood, A.N.; Iglewski, B.H.; Kornberg, A. Polyphosphate kinase is essential for biofilm development, quorum sensing, and virulence of Pseudomonas aeruginosa. Proc. Natl. Acad. Sci. USA 2000, 97, 9636-9641.

7. McInerney, P.; Mizutani, T.; Shiba, T. Inorganic polyphosphate interacts with ribosomes and promotes translation fidelity in vitro and in vivo. Mol. Microbiol. 2006, 60, 438-447.

8. Kuroda, A.; Nomura, K.; Ohtomo, R.; Kato, J.; Ikeda, T.; Takiguchi, N.; Ohtake, H.; Kornberg, A. Role of inorganic polyphosphate in promoting ribosomal protein degradation by the Lon protease in E. coli. Science 2001, 293, 705-708.

9. Negoda, A.; Negoda, E.; Xian, M.; Reusch, R.N. Role of polyphosphate in regulation of the Streptomyces lividans KcsA channel. Biochim. Biophys. Acta 2009, 1788, 608-614. 
10. Wang, L.; Fraley, C.D.; Faridi, J.; Kornberg, A.; Roth, R.A. Inorganic polyphosphate stimulates mammalian TOR, a kinase involved in the proliferation of mammary cancer cells. Proc. Natl. Acad. Sci. USA 2003, 100, 11249-11254.

11. Smith, S.A.; Mutch, N.J.; Baskar, D.; Rohloff, P.; Docampo, R.; Morrissey, J.H. Polyphosphate modulates blood coagulation and fibrinolysis. Proc. Natl. Acad. Sci. USA 2006, 103, 903-908.

12. Lorenz, B.; Munkner, J.; Oliveira, M.P.; Kuusksalu, A.; Leitao, J.M.; Muller, W.E.; Schroder, H.C. Changes in metabolism of inorganic polyphosphate in rat tissues and human cells during development and apoptosis. Biochim. Biophys. Acta 1997, 1335, 51-60.

13. Hernandez-Ruiz, L.; Gonzalez-Garcia, I.; Castro, C.; Brieva, J.A.; Ruiz, F.A. Inorganic polyphosphate and specific induction of apoptosis in human plasma cells. Haematologica 2006, 91, 1180-1186.

14. Kawano, M.M. Inorganic polyphosphate induces apoptosis specifically in human plasma cells. Haematologica 2006, 91, 1154A.

15. Campos, E.; Facanha, A.; Moraes, J.; da Silva, V.I.; Masuda, A.; Logullo, C. A mitochondrial exopolyphosphatase activity modulated by phosphate demand in Rhipicephalus (Boophilus) microplus embryo. Insect Biochem. Mol. Biol. 2007, 37, 1103-1107.

16. Campos, E.; Facanha, A.; Pessoa, E.P.; da Silva, V.I.; Masuda, A.; Logullo, C. Exopolyphosphatases in nuclear and mitochondrial fractions during the hard tick Rhipicephalus (Boophilus) microplus embryo. Comp. Biochem. Physiol. 2008, 151, 311-316.

17. Kumble, K.D.; Kornberg, A. Endopolyphosphatases for long chain inorganic polyphosphate in yeast and mammals. J. Biol. Chem. 1996, 271, 27146-27151.

18. Huh, W.K.; Falvo, J.V.; Gerke, L.C.; Carroll, A.S.; Howson, R.W.; Weissman, J.S.; O’Shea, E.K. Global analysis of protein localization in budding yeast. Nature 2003, 425, 686-691.

19. Pestov, N.A.; Kulakovskaya, T.V.; Kulaev, I.S. Effects of inactivation of the PPN1 gene on exopolyphosphatases, inorganic polyphosphates and function of mitochondria in the yeast Saccharomyces cerevisiae. FEMS Yeast Res. 2005, 5, 823-828.

20. Beauvoit, B.; Rigoulet, M.; Guerin, B.; Canioni, P. Polyphosphates as a source of high-energy phosphates in yeast mitochondria: A 31P NMR-study. FEBS Lett. 1989, 252, 17-21.

21. Guerrero, F.D.; Nene, V.M.; George, J.E.; Barker, S.C.; Willadsen, P. Sequencing a new target genome: The Boophilus microplus (Acari: Ixodidae) genome project. J. Med. Entomol. 2006, 43, 9-16.

22. Sonenshine, D.E.; Kocan, K.M.; de La, F.J. Tick control: Further thoughts on a research agenda. Trends Parasitol. 2006, 22, 550-551.

23. Fagotto, F. Yolk degradation in tick eggs: I. Occurrence of a cathepsin L-like acid proteinase in yolk spheres. Arch. Insect Biochem. Physiol. 1990, 14, 217-235.

24. Gabel, N.M.; Thomas, V. Evidence for the occurrence and distribution of inorganic polyphosphates in vertebrate tissues. J. Neurochem. 1971, 18, 1229-1242.

25. Pavlov, E.; Zakharian, E.; Bladen, C.; Diao, C.T.M.; Grimbly, C.; Reusch, R.N.; French, R.J. A large, voltage-dependent channel, isolated from mitochondria by water-free chloroform extraction. Biophys. J. 2005, 88, 2614-2625. 
26. Gomes, F.M.; Oliveira, D.M.P.; Motta, L.M.; Ramos, I.B.; Miranda, K.; Machado, E.A. Inorganic polyphosphate inhibits an aspartic protease-like activity in the eggs of Rhodnius prolixus (Stahl) and impairs yolk mobilization in vitro. J. Cell. Physiol. 2010, 222, 606-611.

27. Bate, M.; Arias, A.M. The embryonic origin of imaginal discs in Drosophila. Development 1991, 112, 755-761.

28. Monnerat, A.T.; Machado, M.P.; Vale, B.S.; Soares, M.J.; Lima, J.B.; Lenzi, H.L.; Valle, D. Anopheles albitarsis embryogenesis: Morphological identification of major events. Mem. Inst. Oswaldo Cruz 2002, 97, 589-596.

29. Campos, E.; Moraes, J.; Facanha, A.R.; Moreira, E.; Valle, D.; Abreu, L.; Manso, P.P.; Nascimento, A.; Pelajo-Machado, M.; Lenzi, H.; Masuda, A.; Vaz, I.S.; Logullo, C. Kinetics of energy source utilization in Boophilus microplus (Canestrini, 1887) (Acari: Ixodidae) embryonic development. Vet. Parasitol. 2006, 138, 349-357.

30. Rodrigues, C.O.; Ruiz, F.A.; Vieira, M.; Hill, J.E.; Docampo, R. An acidocalcisomal exopolyphosphatase from Leishmania major with high affinity for short chain polyphosphate. J. Biol. Chem. 2002, 277, 50899-50906.

31. Lichko, L.P.; Kulakovskaya, T.V.; Kulaev, I.S. Membrane-bound and soluble polyphosphatases of mitochondria of Saccharomyces cerevisiae: identification and comparative characterization. Biochim. Biophys. Acta 1998, 1372, 153-162.

32. Pavlov, E.; Aschar-Sobbi, R.; Campanella, M.; Turner, R.J.; Gómes-García, M.; Abramov, A.Y. Inorganic polyphosphate and energy metabolism in mammalian cells. J. Biol. Chem. 2010, 285, 9420-9428.

33. Abramov, A.Y.; Fraley, C.; Diao, C.T.; Winkfein, R.; Colicos, M.A.; Duchen, M.R.; French, R.J.; Pavlov, E. Targeted polyphosphatase expression alters mitochondrial metabolism and inhibits calcium-dependent cell death. Proc. Natl. Acad. Sci. USA 2007, 104, 18091-18096.

34. Reusch, N.M.; Sadoff, H.L. Putative structure and functions of a poly-beta-hydroxybutyrate/ calcium polyphosphate channel in bacterial plasma membranes. Proc. Natl. Acad. Sci. USA 1988, $85,4176-4180$.

35. Fiske, C.F.; Subbarow, Y. The colorimetric determination of phosphorus. J. Biol. Chem. 1925, 66, 375-400.

36. Bradford, M.M. A rapid and sensitive method for the quantitation of microgram quantities of protein utilizing the principle of protein-dye binding. Anal. Biochem. 1976, 72, 248-254.

(C) 2011 by the authors; licensee MDPI, Basel, Switzerland. This article is an open access article distributed under the terms and conditions of the Creative Commons Attribution license (http://creativecommons.org/licenses/by/3.0/). 